\title{
Sub-MICs of Carum copticum and Thymus vulgaris influence virulence factors and biofilm formation in Candida spp
}

\author{
Mohd SA Khan ${ }^{1,2^{*}}$, Iqbal Ahmad ${ }^{2}$, Swaranjit S Cameotra ${ }^{3}$ and Francien Botha ${ }^{1}$
}

\begin{abstract}
Background: Emergence of drug-resistant strains of Candida and inefficiency of conventional antifungal therapy has necessitated the search for alternative and new antifungal agents. Inhibition of virulence and biofilm are the potential drug targets. In this study, the oils of Carum copticum, Thymus vulgaris and their major active compound thymol as revealed by Gas chromatography and gas chromatography-mass spectrometry (GC-GC/MS) analysis were tested for their inhibitory activity against growth to determine sub-MIC values against 27 drug-resistant strains of Candida spp.

Methods: Brothmacrodilution method was used for determination of MIC of test oils against Candida strains. The spectrophotometric methods were used for detection and inhibition assays for virulence factors in Candida spp. Light and electron microscopy was performed to observe morphological effects of oils on biofilms. GC-GC/MS were used to evaluate the major active compounds of test oils.

Results: Virulence factors like proteinase and haemolysin were detected in 18 strains, both in solid and liquid media. A $70 \%$ of the test strains exhibited hydrophobicity and formed moderate to strong biofilms $\left(\mathrm{OD}_{280} 0.5->1.0\right)$. Test oils exhibited MICs in the range of $45-360 \mu \mathrm{g} \cdot \mathrm{mL}^{-1}$ against the majority of test strains. All the oils at $0.25 \times$ and $0.5 \times \mathrm{MICs}$ induced $>70 \%$ reduction in the cell surface hydrophobicity, proteinase and haemolysin production. At $0.5 \times \mathrm{MIC}$, thymol and T. vulgaris were most inhibitory against biofilm formation. At sub-MICs electron microscopic studies revealed the deformity of complex structures of biofilms formed and cell membranes appeared to be the target site of these agents.

Conclusions: Therefore, our findings have highlighted the concentration dependent activity of oils of C. copticum and T. vulgaris against virulence factors and biofilms in proteinase and haemolysin producing drug-resistant strains of Candida spp. The above activities of test oils are supposed to be mainly contributed due to their major active compound thymol. Further mechanism involving anti-proteinase, anti-haemolysin and anti-biofilm activities of these oils and compounds are to be explored for possible exploitation in combating Candida infections.
\end{abstract}

\section{Background}

Candida spp cause infections of immuno-competent individuals and, are frequently life-threatening, in particular in immuno-compromised individuals, whose numbers are constantly increasing due to organ transplant, chemotherapy, or, AIDS and Hepatitis C [1]. Candida spp now ranks as fourth most common cause of nosocomial bloodstream infection in the United States and the attributable mortality

\footnotetext{
*Correspondence: khanmsa@hotmail.com

'Phytomedicine Programme, Department of Paraclinical Sciences, University of Pretoria, Pretoria 0110, South Africa

${ }^{2}$ Department of Agricultural Microbiology, Aligarh Muslim University, Aligarh 202002, India

Full list of author information is available at the end of the article
}

rate is $35 \%$ [2]. About $70 \%$ of women experience vaginal infections caused by Candida spp and 20\% of them suffered from recurrence [3]. Candida albicans accounts for the majority of cases with candidiasis, but an increasing number of infections due to non-albicans spp. have been reported [4]. The most commonly isolated nonalbicans Candida are C. glabrata (causing 3\%-35\% of all candidemias), followed by C. tropicalis, C. parapsilosis, C. Krusei, and other Candida spp [5,6]. Moreover, the majority of such manifestations of candidiasis are associated in one way or another with the formation of Candida biofilms on the surfaces of inert or biological surfaces [7]. Biofilm cells are notoriously resistant to antimicrobial agents and withstand host immune defenses [8]. 
Many of the polyenes and azoles used to treat such infections have several problems namely undesirable side effects, rapid development of drug-resistance and inefficacy against biofilm forming pathogens [9]. This scenario has exacerbated the need for alternative antifungal therapy and search for new and better agents that target fundamental biological processes and/or pathogenic determinants. It is expected that compounds with anti-virulence and antibiofilm activities may reduce or interfere with the production of one or more virulence factors and tolerance to drugs at lower doses. This will attenuate pathogenicity of microorganism without producing killing pressure and therefore development of resistance could be overcome. Further biofilm inhibition by the compound will also reduce the persistence and increased tolerance to drugs.

In the past decade interest in natural products has increased, and medicinal plants have been investigated for various biological activities and therapeutic potentials [10-13]. Oils of Carum copticum and Thymus vulgaris have been shown to exhibit antifungal activities against pathogenic isolates of Candida spp [14-21]. However little or no information is available on anti-infective properties of these oils at non-growth inhibitory concentrations i.e. sub-MICs. Therefore, one way to demonstrate these oils to be effective antipathogenic agents is to check their ability to arrest the production of extracellular enzymatic virulence factors in Candida spp that assist the pathogen to colonize host tissues, cause disease, and overcome host defenses [22].

Multiple characteristics of $C$. albicans have been proposed as virulence traits including the phenotypic variability, germination, adherence to inert and biological substrates, cell-surface hydrophobicity and production of secreted hydrolytic enzymes such as aspartyl proteinases, phospholipases and haemolysin [23-26]. On the other hand it has been speculated that biofilms account for as much as $65 \%$ of all microbial infections [27]. Since, ability of a pathogen to form biofilm is intimately associated with its adhering potential (cell surface hydrophobicity) and production of virulence factors; we assumed that essential oils or compounds exhibiting anti-virulence activity might be effective against Candida biofilms too.

Therefore, first we attempted to assess the production of virulence factors (proteinase and haemolysins) and also cell surface hydrophobicity and biofilm formation in Candida spp obtained from various clinical origin. Secondly, sub-MICs of the oils of C. copticum and $T$. vulgaris and their major active compound thymol were determined to evaluate in vitro efficacy in influencing virulence and biofilm formation by Candida spp. Fluconazole was used as control drug in the study.

\section{Methods}

\section{Organisms and media}

In this study, 23 isolates of clinical origin and 4 reference strains of Candida spp exhibiting varying level of resistance to antifungal drugs with $\mathrm{MIC}$ of fluconazole ranging from 128 to $256 \mu$ g.mL $\mathrm{mL}^{-1}$ [28] were included. The clinical isolates of C. albicans (CA01-18), C. glabrata (01,02), C. krusei 01 and $C$. tropicalis $(01,02)$ were isolated from patients with vaginitis, urinary tract infections and candidemia attending the Jawaharlal Nehru Medical College and Hospital, Aligarh Muslim University, Aligarh. All patients gave written informed consent and the use of these isolates in our study was approved by the institutional ethics committee of the Jawaharlal Nehru Medical College and Hospital, Aligarh Muslim University. Candida albicans NRRLY12983 was kindly provided by the fungal culture collection at Agricultural Research Service, USDA, Peoria, USA. The reference strain C. albicans SC5314 exhibiting production of various virulence factors was provided by Prof. Rajendra Prasad, Jawaharlal Nehru University, New Delhi. Strains C. albicans MTCC183 and C. glabrata MTCC3019 were purchased from the Microbial Type Culture Collection, Institute of Microbial Technology, Chandigarh, India. The test strains were maintained on Sabouraud dextrose agar (SDA) slants at $4^{\circ} \mathrm{C}$ and sub-cultured in the Sabouraud dextrose broth (SDB) prior to use.

\section{Plant essential oils and drugs}

Oils of Carum copticum and Thymus vulgaris were purchased from Aroma Sales Corporation, New Delhi, India. Whereas, thymol (minimum assay 99\%) and drug powder of fluconazole were purchased from Hi-media Laboratories, India and Pfizer Co, Mumbai, India, respectively. Stock solutions of fluconazole was prepared in dimethyl sulphoxide (DMSO) at a concentration of $25 \mathrm{mg} \cdot \mathrm{mL}^{-1}$ and stored at $-20^{\circ} \mathrm{C}$ until used. Essential oils were diluted ten-fold in 1\% DMSO and used in the assays.

\section{Detection of virulence factors in isolates of Candida spp Proteinase assay}

Production of extracellular proteinase was assessed by the method of Aoki et al. [29]. using BSA agar plates. Briefly, $60 \mathrm{~mL}$ of a solution containing $\mathrm{MgSO}_{4} \cdot 7 \mathrm{H}_{2} \mathrm{O}$ $0.04 \mathrm{~g}, \mathrm{~K}_{2} \mathrm{HPO}_{4} 0.5 \mathrm{~g}, \mathrm{NaCl} 0.2 \mathrm{~g}$, yeast extract $0.2 \mathrm{~g}$, glucose $4.0 \mathrm{~g}$ and BSA (Hi-Media) $0.5 \mathrm{~g}$; was prepared and the $\mathrm{pH}$ was adjusted to 3.5 with $1 \mathrm{~N}$ HCL. This solution was filter sterilized and mixed with $140 \mathrm{ml}$ of autoclaved melted agar to prepare the BSA agar plates. Amounts of $10 \mu \mathrm{L}$ of yeast suspension $\left(1.0 \times 10^{6} \mathrm{cfu}^{\mathrm{m} \mathrm{mL}^{-1}}\right)$ were spot inoculated on the BSA agar plates and incubated at $37^{\circ} \mathrm{C}$ for 5 days. After incubation, the plates were stained with $0.1 \%$ amido black dye and destained with $15 \%$ acetic 
acid, and the clear zone was measured. Proteinase activity ( $\mathrm{pZ}$ values) was calculated in terms of the ratio of the diameter of the colony to the total diameter of colony plus zone of solubilization.

The proteinase production in liquid medium was determined using the modified method of Kuriyama et al. [30]. Briefly, $50 \mathrm{ml}$ Erlenmeyer flasks containing $10 \mathrm{ml}$ of induction medium as described by MacDonald \& Odd [31] was inoculated with $100 \mu \mathrm{l}$ of Candida cells $\left(1.0 \times 10^{6} \mathrm{cfu} \mathrm{ml}^{-1}\right)$ and incubated at $26^{\circ} \mathrm{C}$ for 7 days at $160 \mathrm{rpm}$. The broth culture was centrifuged at $5000 \mathrm{rpm}$ for $30 \mathrm{~min}$ to obtain supernatant. Furthermore, $200 \mu \mathrm{L}$ of supernatant was mixed with $800 \mu \mathrm{L}$ of substrate [1\% (w/v) BSA in $0.025 \mathrm{M}$ sodium citrate buffer, $\mathrm{pH}$ 3.2] and incubated at $37^{\circ} \mathrm{C}$ for $3 \mathrm{~h}$. The reaction was halted by the addition of $2.0 \mathrm{~mL}$ of $5 \%$ trichloroacetic acid (TCA) resulting in precipitation of undigested BSA. Tubes were kept at ice for $30 \mathrm{~min}$ and centrifuged at $2000 \mathrm{~g}$ for 20 min. Proteolysis was determined by measuring the absorbance of soluble peptides at $280_{\mathrm{nm}}$. A control was run by mixing substrate to supernatant and immediately reaction was stopped by adding TCA. The absorbance value of control was subtracted from test samples to obtain values for enzyme activity.

\section{Haemolysis assay}

Haemolysin production was evaluated using a modified method of Luo et al. [32]. The blood agar plates were prepared by adding $7 \mathrm{ml}$ of fresh sheep blood suspended in sterile phosphate buffer saline (PBS) to $100 \mathrm{~mL}$ of SDA supplemented with $3 \%(\mathrm{w} / \mathrm{v})$ glucose. Amounts of $10 \mu \mathrm{l}$ of yeast suspension $\left(1.0 \times 10^{6} \mathrm{cfu} \cdot \mathrm{mL}^{-1}\right)$ were spot inoculated on the blood agar plates and incubated at $37^{\circ} \mathrm{C}$ in $5 \% \mathrm{CO}_{2}$ for $48 \mathrm{~h}$. After incubation, plates were scored for the presence of transluscent ring and or a greenish black halo circumscribing the inoculum growth. Haemolysin activity ( $\mathrm{pZ}$ values) was calculated in terms of the ratio of the diameter of the colony to the total diameter of colony plus zone of halo.

The haemolysin production in liquid medium was determined using the method of Manns et al. [33] with some modifications. The erythrocytes were harvested by centrifugation of freshly obtained sheep blood for $10 \mathrm{~min}$ at $3000 \mathrm{rpm}$, and washed three times in PBS. To the pellet, PBS was added to yield a $10 \%(\mathrm{v} / \mathrm{v})$ erythrocytes/PBS suspension. The $10 \%$ suspension was then diluted 10 times in PBS. Candida cells were grown in SDB [8\% $(w / v)$ glucose] for 4 days at $37^{\circ} \mathrm{C}$. The broth cultures were centrifuged at $5000 \mathrm{~g}$ for $30 \mathrm{~min}$ to obtain supernatant. Furthermore, the culture supernatant and RBC suspension were mixed in $1: 1$ ratio and incubated at $37^{\circ} \mathrm{C}$ for $4 \mathrm{~h}$. Triton $\mathrm{X}-100[0.1 \%(\mathrm{v} / \mathrm{v})$ in $\mathrm{PBS}]$ was used as a positive control whereas $1 \%$ DMSO and PBS were used as negative controls. Tubes were centrifuged at $2000 \mathrm{~g}$ for
$10 \mathrm{~min}$ and the absorbances of supernatants were read at $540_{\mathrm{nm}}$. The percentage of haemolysis was calculated as: $[\{(\mathrm{A}-\mathrm{B}) /(\mathrm{C}-\mathrm{B})\} \times 100]$. Where, $\mathrm{A}$ and $\mathrm{B}$ are the absorbance values of supernatant from the test sample and PBS (solvent control) respectively and $\mathrm{C}$ is the absorbance value of supernatant from the sample after $100 \%$ lysis.

\section{Detection of cell surface hydrophobicity and biofilm formation in the isolates of Candida spp Cell surface hydrophobicity}

The method of microbial adhesion to hydrocarbons (MATH) as described by Rosenberg et al. [34] was used with some modifications to determine the \% $\mathrm{CSH}$ of Candida cells. Briefly, Candida cells were grown on SDA plates amended with $0.5 \times$ and $0.25 \times$ MICs of test agents at $25^{\circ} \mathrm{C}$ for $48 \mathrm{~h}$. Candida cells grown on SDA plates without amendment of test agents were considered as untreated control. Yeast suspensions were made in PBS $\left(\mathrm{A}_{520}\right.$ of 0.400$)$ and allowed to contact with xylene in 5:1 ratio. The mixtures were vortexed for $1 \mathrm{~min}$ at room temperature and then allowed to separate the two phases for $10 \mathrm{~min}$. The absorbance of aqueous phase was read at $520 \mathrm{~nm}$. The \%CSH was calculated as follows; $\% C S H=\left[\left(A_{i}-A_{f}\right) / A_{i}\right] \times 100$. Where $A_{i}$ and $A_{f}$ are the absorbance values of aqueous yeast suspension at $520 \mathrm{~nm}$ before and after contacting yeast suspension to the organic phase.

\section{Biofilm formation}

The strains were evaluated by 96 well microtiter plates (HiMedia, Laboratories, Mumbai, India) based XTT reduction assay for their ability to form biofilms using the method of Ramage et al. [35] with some modifications. Briefly, Candida cells were grown in SDB (glucose $8 \%$ $[\mathrm{w} / \mathrm{v}]$ ) at $37^{\circ} \mathrm{C}$ for $24 \mathrm{~h}$. Cells were harvested and resuspended in RPMI 1640 medium with L-glutamine but without bicarbonate and buffered to $\mathrm{pH} 7.0$ with MOPS to a cell density of $1.5 \times 10^{6} \mathrm{cfu} \cdot \mathrm{mL}^{-1}$. Biofilms were formed by adding $100 \mu \mathrm{L}$ of this standardized cell suspension to wells of microtiter plates and incubating at $37^{\circ} \mathrm{C}$ for $48 \mathrm{~h}$. After biofilm formation, the medium was aspirated gently, and non-adherent cells were removed by washing the biofilms three times with sterile PBS. Further biofilm formation was analysed by XTT reduction assay. Briefly, $0.091 \mathrm{~mL}$ of XTT (Sigma, N. Delhi) $\left(1 \mu \mathrm{g} . \mathrm{mL}^{-1}\right.$, prepared in PBS) and $0.009 \mathrm{~mL}$ of menadione (Sigma, N. Delhi) (1 mmol. $\mathrm{L}^{-1}$, prepared in acetone) was added to each well and incubated in the dark for $4 \mathrm{~h}$. The colorimetric change was measured at $492 \mathrm{~nm}$ using a Labsystem Multiskan Ex MTP Reader.

\section{Light microscopy of biofilms formed}

Polyvinyl chloride catheter discs (15 mm diameter) were placed in 6 well tissue culture plates. Wells of the plates 
were dispensed with $1 \mathrm{~mL}$ of RPMI medium and $1 \mathrm{ml}$ of standardized yeast cell suspension was added to each well and incubated at $37^{\circ} \mathrm{C}$ for $48 \mathrm{~h}$. After the formation of biofilm, medium was discarded and discs were washed three times with sterile PBS and air dried. The discs were visualized under bright field light microscope (Olympus, Japan) at $40 \mathrm{X}$.

\section{Gas chromatography and gas chromatography-mass spectrometry analysis of essential oils}

The percentage composition of oils and compounds was determined by GC-FID and the compounds were identified by GC-MS. GC analysis was carried out on a Shimadzu 2010 Gas Chromatograph equipped with an FID and $25 \mathrm{~m} \times 0.25 \mathrm{~mm} \times 0.25 \mu \mathrm{m}$ WCOT column coated with diethylene glycol (AB-Innowax, 7031428, Japan). Injector temperature was set at $270^{\circ} \mathrm{C}$ and detector at $280^{\circ} \mathrm{C}$. Nitrogen was used as a carrier gas at a flow rate of $3.0 \mathrm{ml} / \mathrm{min}$ at a column pressure of $74.9 \mathrm{kPa} .0 .2 \mu \mathrm{L}$ of sample were injected into column with a split ratio of 90.0. The linear temperature program of $60^{\circ} \mathrm{C}$ to $230^{\circ} \mathrm{C}$ set at a rate of $3^{\circ} \mathrm{C} \mathrm{min}^{-1}$ with hold time at $230^{\circ} \mathrm{C}$ for 10 minutes. The samples were then analyzed on the same Shimadzu instrument fitted with the same column and following the same temperature program as above. MS parameters used were: ionisation voltage (EI) $70 \mathrm{eV}$, peak width $2 \mathrm{~s}$, mass range 40-600 amu and detector voltage $1.5 \mathrm{~V}$. Results were based on GC-FID. Peak identification was carried out by comparison of the mass spectra with database of NIST05, NBS75K and Wiley 8 libraries. Identification of compounds was confirmed by comparison of their relative retention indices relative to $(\mathrm{C} 8-\mathrm{C} 22)$ n-alkanes with literature data or authentic compounds [36-38].

\section{Determination of sub-MICs essential oils against the strains of Candida spp}

For MIC determination of essential oils, $10 \mu \mathrm{L}$ of yeast suspension (0.5 McFarland) was added to $1 \mathrm{~mL}$ SDB containing serially diluted test oils along with $0.1 \%(\mathrm{v} / \mathrm{v})$ Tween 80 and incubated at $37^{\circ} \mathrm{C}$ for $24 \mathrm{~h}$ at $28 \pm 2{ }^{\circ} \mathrm{C}$. MIC was defined as the lowest concentration that inhibited visible growth.

\section{Determination of viability of Candida strains at sub-MICs of oils}

The test strains at a cell density of $1.0 \times 10^{6} \mathrm{cfu}_{\mathrm{mL}} \mathrm{m}^{-1}$ were inoculated in to test tubes containing $10 \mathrm{ml}$ of SDB amended with sub-MICs $(0.5 \times$ and $0.25 \times \mathrm{MICs})$ of test agents for $24 \mathrm{~h}$ at $37^{\circ} \mathrm{C}$. A control was run without test agents but containing yeast inoculum at equal cell density. Viable counts were obtained from the test and control solutions by plating $100 \mu \mathrm{L}$ of 10 -fold serial dilutions onto SDA plates and incubating at $37^{\circ} \mathrm{C}$ for $24 \mathrm{~h}$.
Inhibition of virulence factors by essential oils at sub-MICs

\section{Inhibition of proteinase production}

Briefly, $50 \mathrm{ml}$ Erlenmeyer flasks containing $10 \mathrm{ml}$ of induction medium as described by MacDonald and Odds [31] with and without sub-MICs $(0.5 \times$ and $0.25 \times$ MIC) of test agents were inoculated with $100 \mu \mathrm{L}$ of Candida cells $\left(1.0 \times 10^{6}\right.$ cfu.mL $\left.{ }^{-1}\right)$ and incubated at $26^{\circ} \mathrm{C}$ for 7 days at $160 \mathrm{rpm}$. The inhibition of proteinase production by oils was determined using the modified method of Kuriyama et al. [30] as mentioned earlier. The absorbance value of untreated control was subtracted from treated samples to obtain values for enzyme activity. Each experiment was conducted three times with three replicates per experiment and data are presented as percent reduction of absorbance values in treated sample over untreated control.

\section{Inhibition of haemolysin production}

Candida cells were grown in SDB [8\% (w/v) glucose] containing $0.5 \times$ and $0.25 \times$ MIC of test agents for 4 days at $37^{\circ} \mathrm{C}$. The solution without test agents was considered as untreated control. Further, the inhibition of haemolysin production by oils was carried out using the method of Manns et al. [33] with some modifications as mentioned earlier. Each experiment was conducted three times with three replicates per experiment and mean absorbance values were used to calculate the percent reduction of haemolysin in treated samples over untreated controls.

\section{Inhibition of biofilm formation by essential oils at sub-MICs}

\section{Effect of oils on biofilm formation}

The effect of different sub-MICs of oils and drugs $(0.5 \times$ MIC, $0.25 \times$ MIC) on the ability of Candida cells to form biofilm was determined by the modified method of Ramage et al. [35] with some modifications. Volumes of $0.1 \mathrm{~mL}$ of test agents ( $2 \times$ final concentrations) in RPMI 1640 medium was added to each well of microtiter plates. Subsequently, $0.1 \mathrm{~mL}$ of standardized yeast cell suspension was added and plates were incubated at $37^{\circ} \mathrm{C}$ for $48 \mathrm{~h}$. Antifungal agent-free wells served as positive controls for biofilm growth. After incubation, the medium and non-adherent cells were removed from wells and washed three times with sterile PBS. Further biofilm formation was analysed by XTT reduction assay. Absorbance values were used to measure the inhibition of biofilm formation as follows: (mean $\mathrm{OD}_{492}$ of treated well/mean $\mathrm{OD}_{492}$ of untreated control well) $\times 100$.

\section{Scanning electron microscopy of biofilm cells formed in the presence of oils}

For examination by SEM, Candida biofilm cells were grown on catheter discs in the presence of $0.5 \times$ and 
$0.25 \times$ MICs of test agents for $48 \mathrm{~h}$ at $37^{\circ} \mathrm{C}$ as described in the preceding section. Biofilms grown in the absence of test agents served as control. After washing with PBS, discs containing biofilms were placed in a fixative solution of $5 \%$ glutaraldehyde in cacodylate buffer in a graded series of ethanol, immersed in hexamethyldisilazane, and finally air dried overnight at room temperature.
Transmission electron microscopy of planktonic cells

Structural changes produced by test compounds towards fungal cell were evaluated using transmission electron microscopy. Briefly, $10 \mathrm{~mL}$ of SDB treated with $0.5 \times$ and $0.25 \times$ MICs of test agents was inoculated with $100 \mu \mathrm{L}$ of cell suspension ( 0.5 McFarland) and incubated at $37^{\circ} \mathrm{C}$ for $48 \mathrm{~h}$ at $120 \mathrm{rpm}$. Control sample did not receive

Table 1 Detection of biofilm formation and extracellular production of virulence factors in the strains of Candida spp

\begin{tabular}{|c|c|c|c|c|c|c|c|c|}
\hline \multirow[t]{4}{*}{ Test strains } & \multirow{4}{*}{$\begin{array}{l}\text { Clinical } \\
\text { condition }\end{array}$} & \multirow{4}{*}{$\begin{array}{l}\text { Resistance } \\
\text { pattern }\end{array}$} & \multirow[t]{4}{*}{$\% \mathrm{CSH}$} & \multirow{4}{*}{$\begin{array}{l}\text { Biofilm } \\
\text { formation } \\
\left(O D_{490}\right)^{*}\end{array}$} & \multicolumn{4}{|c|}{ Virulence factors production } \\
\hline & & & & & \multirow{2}{*}{\multicolumn{2}{|c|}{$\begin{array}{l}\text { Solid medium } \\
\text { Activity inde } \times(\mathrm{pZ})\end{array}$}} & \multirow{2}{*}{\multicolumn{2}{|c|}{ Liquid medium }} \\
\hline & & & & & & & & \\
\hline & & & & & Proteinase & Haemolysin & $\begin{array}{l}\text { Proteinase } \\
\left(\mathrm{OD}_{280}\right) \#\end{array}$ & $\%$ haemolysis \\
\hline \multicolumn{9}{|l|}{ C. albicans } \\
\hline C. albicans 01 & Candidemia & KTZ, ICZ, FLZ & $41.30 \pm 3.75$ & $0.49 \pm 0.04$ & $0.50 \pm 0.04$ & $0.63 \pm 0.05$ & $1.23 \pm 0.11$ & 41.52 \\
\hline C. albicans 02 & -Do- & KTZ, ICZ, FLZ & ND & $0.05 \pm 0.01$ & $0.78 \pm 0.04$ & $0.60 \pm 0.05$ & $0.45 \pm 0.02$ & 29.10 \\
\hline C. albicans 03 & -Do- & $\mathrm{KTZ}, \mathrm{ICZ}, \mathrm{FLZ}$ & $62.11 \pm 2.31$ & $0.59 \pm 0.02$ & $0.55 \pm 0.03$ & $1.0 \pm 0.00$ & $1.35 \pm 0.13$ & ND \\
\hline C. albicans 04 & -Do- & KTZ, ICZ, FLZ & $61.75 \pm 2.85$ & $1.36 \pm 0.66$ & $0.80 \pm 0.05$ & $1.0 \pm 0.00$ & $0.42 \pm 0.04$ & ND \\
\hline C. albicans 05 & Urine & $\mathrm{AMB}, \mathrm{KTZ}, \mathrm{ICZ}, \mathrm{FLZ}$ & $59.78 \pm 4.31$ & $1.0 \pm 0.08$ & $1.0 \pm 0.00$ & $0.68 \pm 0.05$ & Nil & 74.68 \\
\hline C. albicans 06 & -Do- & AMB, KTZ, ICZ, FLZ & $55.43 \pm 3.38$ & $1.15 \pm 0.10$ & $0.60 \pm 0.04$ & $1.0 \pm 0.00$ & $0.95 \pm 0.04$ & ND \\
\hline C. albicans 07 & -Do- & $\mathrm{AMB}, \mathrm{KTZ}, \mathrm{ICZ}, \mathrm{FLZ}$ & $66.21 \pm 2.97$ & $0.60 \pm 0.03$ & $0.71 \pm 0.06$ & $1.0 \pm 0.00$ & $0.44 \pm 0.03$ & ND \\
\hline C. albicans 08 & -Do- & $\mathrm{KTZ}, \mathrm{ICZ}, \mathrm{FLZ}$ & ND & $0.28 \pm 0.04$ & $0.52 \pm 0.05$ & $1.0 \pm 0.00$ & $1.18 \pm 0.14$ & ND \\
\hline C. albicans 09 & -Do- & AMB, KTZ, ICZ, FLZ & $55.10 \pm 2.75$ & $1.12 \pm 0.09$ & $0.77 \pm 0.04$ & $0.83 \pm 0.05$ & $0.85 \pm 0.06$ & 25.84 \\
\hline C. albicans 10 & Vaginitis & $\mathrm{AMB}, \mathrm{KTZ}, \mathrm{ICZ}, \mathrm{FLZ}$ & ND & $0.05 \pm 0.01$ & $0.66 \pm 0.05$ & $1.0 \pm 0.00$ & $1.37 \pm 0.22$ & ND \\
\hline C. albicans 11 & -Do- & $\mathrm{AMB}, \mathrm{KTZ}, \mathrm{ICZ}, \mathrm{FLZ}$ & ND & 0.2650 .03 & $0.75 \pm 0.04$ & $0.63 \pm 0.04$ & $0.61 \pm 0.05$ & 37.33 \\
\hline C. albicans 12 & -Do- & $\mathrm{AMB}, \mathrm{KTZ}, \mathrm{ICZ}, \mathrm{FLZ}$ & ND & $0.35 \pm 0.05$ & $0.71 \pm 0.04$ & $1.0 \pm 0.00$ & $1.00 \pm 0.09$ & ND \\
\hline C. albicans 13 & -Do- & $\mathrm{AMB}, \mathrm{KTZ}, \mathrm{ICZ}, \mathrm{FLZ}$ & $25.78 \pm 2.98$ & $0.67 \pm 0.08$ & $0.78 \pm 0.05$ & $1.0 \pm 0.00$ & $1.15 \pm 0.10$ & ND \\
\hline C. albicans 14 & -Do- & $\mathrm{AMB}, \mathrm{KTZ}, \mathrm{ICZ}, \mathrm{FLZ}$ & $33.45 \pm 3.71$ & $0.62 \pm 0.05$ & $0.73 \pm 0.06$ & $1.0 \pm 0.00$ & $1.18 \pm 0.10$ & ND \\
\hline C. albicans 15 & -Do- & AMB, KTZ, ICZ, FLZ & $44.59 \pm 4.97$ & $0.55 \pm 0.04$ & $1.0 \pm 0.00$ & $1.0 \pm 0.00$ & Nil & ND \\
\hline C. albicans 16 & -Do- & $\mathrm{AMB}, \mathrm{KTZ}, \mathrm{ICZ}, \mathrm{FLZ}$ & $24.76 \pm 2.38$ & $0.58 \pm 0.01$ & $1.0 \pm 0.00$ & $0.65 \pm 0.05$ & Nil & 83.18 \\
\hline C. albicans 17 & -Do- & $\mathrm{AMB}, \mathrm{KTZ}, \mathrm{ICZ}, \mathrm{FLZ}$ & $40.90 \pm 3.36$ & $0.78 \pm 0.02$ & $1.0 \pm 0.00$ & $0.64 \pm 0.04$ & Nil & 81.25 \\
\hline C. albicans 18 & -Do- & $\mathrm{AMB}, \mathrm{KTZ}, \mathrm{ICZ}, \mathrm{FLZ}$ & $53.45 \pm 4.97$ & $1.32 \pm 0.07$ & $1.0 \pm 0.00$ & $0.68 \pm 0.05$ & Nil & 91.45 \\
\hline C. albicans NRRLY12983 & Reference strain & KTZ, ICZ, FLZ & $25.78 \pm .17$ & $1.15 \pm 0.10$ & $0.50 \pm 0.04$ & $0.73 \pm 0.06$ & $1.21 \pm 0.10$ & 24.32 \\
\hline C. albicans MTCC183 & -Do- & KTZ, ICZ, FLZ & $35.60 \pm 1.76$ & $0.60 \pm 0.03$ & $1.0 \pm 0.00$ & $0.82 \pm 0.06$ & $1.35 \pm 0.12$ & 24.93 \\
\hline C. albicans SC5314 & -Do- & - & $63.28 \pm 5.18$ & $1.09 \pm 0.01$ & $0.58 \pm 0.05$ & $0.55 \pm 0.06$ & $1.06 \pm 0.09$ & 74.45 \\
\hline \multicolumn{9}{|l|}{ Non albicans-Candida } \\
\hline C. glabrata 01 & Vaginitis & $\mathrm{KTC}, \mathrm{ICZ}, \mathrm{FLZ}$ & $65.39 \pm 6.1$ & $0.05 \pm 0.01$ & $1.0 \pm 0.00$ & $1.0 \pm 0.00$ & $0.20 \pm 0.05$ & ND \\
\hline C. glabrata 02 & -Do- & $\mathrm{AMB}, \mathrm{KTZ}, \mathrm{ICZ}, \mathrm{FLZ}$ & ND & $0.04 \pm 0.09$ & $1.0 \pm 0.00$ & $1.0 \pm 0.00$ & Nil & 15.96 \\
\hline C. glabrata MTCC3019 & Reference strain & KTC, ICZ, FLZ & ND & $0.05 \pm 0.09$ & $1.0 \pm 0.00$ & $1.0 \pm 0.00$ & Nil & ND \\
\hline C. krusei 01 & Vaginitis & $\mathrm{AMB}, \mathrm{KTZ}, \mathrm{ICZ}, \mathrm{FLZ}$ & $41.22 \pm 3.38$ & $0.05 \pm 0.01$ & $0.55 \pm 0.04$ & $0.61 \pm 0.04$ & Nil & 28.95 \\
\hline C. tropicalis 01 & Candidemia & $\mathrm{ICZ}, \mathrm{FLZ}$ & $62.99 \pm 5.10$ & $0.14 \pm 0.01$ & $0.56 \pm 0.04$ & $0.63 \pm 0.05$ & $0.98 \pm 0.07$ & 60.42 \\
\hline C. tropicalis 02 & Vaginitis & $\mathrm{ICZ}, \mathrm{FLZ}$ & ND & $0.06 \pm 0.02$ & $0.65 \pm 0.05$ & $0.66 \pm 0.05$ & $0.57 \pm 0.06$ & 34.27 \\
\hline
\end{tabular}

$\mathrm{pZ}=$ (zone of diameter of colony)/(zone of diameter of colony + zone of solubilization or precipitation around the colony)

$\mathrm{pZ}=1$; indicates no activity.

*Biofilm formation was considered as Nil for $\mathrm{OD}_{490}<0.1$.

$\mathrm{OD}_{490}$ (0.1-0.5); weak biofilm, $\mathrm{OD}_{490}$ (>0.5-1.0); moderate biofilm, $\mathrm{OD}_{490}(>1.0)$; strong biofilms.

\#Proteinase activity was considered as Nil for $\mathrm{OD}_{280}<0.1$.

$\mathrm{AMB}$; amphotericin $\mathrm{B}, \mathrm{FLZ}$; fluconazole, ICZ; Itraconazole, $\mathrm{KTZ}$; ketoconazole.

ND; not detected. 


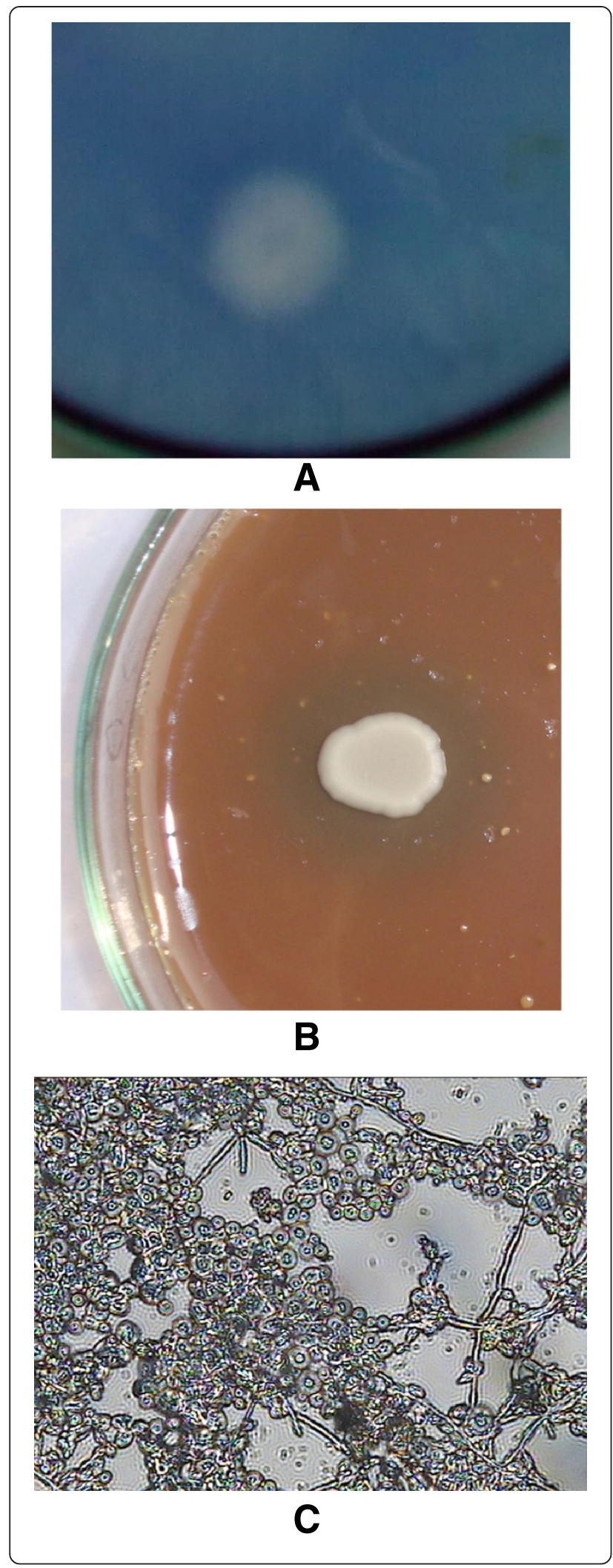

Figure 1 Detection of extracellular expression of virulence factors in the strains of Candida spp in solid media. (A) Proteinase production in C. albicans 04. (B) Haemolysin production in C. albicans 02. (C) Biofilm formation by C. albicans 04 on catheter discs in $48 \mathrm{~h}$, under $40 \times$ light microscope (mature biofilms exhibiting dense matrix, hyphae and embedded yeast cells).

treatment. The obtained cell pellets were fixed with 2.5\% glutaraldehyde in $0.1 \mathrm{M}$ cacodylate buffer $(\mathrm{pH}$ 7.2) for $24 \mathrm{~h}$ at room temperature. Post fixation was carried out in $1 \%$ osmium tetroxide in cacodylate buffer. Samples were dehydrated in acetone and embedded in epon. Ultra thin sections were stained with $12.5 \%$ alcoholic uranyl acetate and viewed under Morgagni 268D transmission electron microscope at $80 \mathrm{kv}$.

\section{Statistical analysis}

All the experiments were performed three times with three replicates per experiment and data are expressed as mean \pm standard deviation. Statistical significance of the differences was determined by the one way ANOVA test using Minitab (V.11.0 for Windows). Reduction in \% CSH in test strains in the presence of oils was compared to untreated control by one way ANOVA using Duncan's method. Similarly, difference in $\log \mathrm{cfu} / \mathrm{ml}$ of treated samples $(0.5 \times$ and $0.25 \times \mathrm{MICs})$ was compared to untreated control. $P$-values of $<0.05$ were considered as statistically significant.

\section{Results}

\section{Detection of proteinase and haemolysin production}

As presented in Table 1 and Figure $1 \mathrm{~A}, \mathrm{~B}$, among the test strains of C. albicans $71 \%$ were positive for proteinase production and $52 \%$ were for haemolysin production on solid medium. Among the strains of non-albicans Candida (NAC) production of proteinase and haemolysin was recorded in 3 different strains.

Production of proteinase and haemolysin in liquid medium among the strains of Candida spp is depicted in Table 1. Production of proteinase was recorded in $75 \%$ of the test strains of C. albicans. Seven strains from different clinical origin and three reference strains exhibited higher proteolytic activity with absorbance values $(>1.0)$. Haemolysin production was recorded in $52 \%$ of the $C$. albicans strains. Among the NACs, four test strains exhibited haemolysin production in the range of 15.96 to $60.42 \%$. All the strains producing protease on solid medium could also produce in liquid medium except three strains C. albicans MTCC12983, C. glabrata 01 and C. tropicalis 02. Similar trend was also observed in the production of haemolysin on solid and liquid medium. 
Detection of cell surface hydrophobicity of Candida cells and their ability to form biofilms

As evident from Table $176 \%$ of the test strains of $C$. albicans were positive for CSH (24.76 to $66.21 \% \mathrm{CSH}$ ) as well as proteinase production $\left(\mathrm{A}_{260} \mathrm{~nm} 0.45\right.$ to 1.61$)$. Among the NACs three strains were hydrophobic with \% CSH ranging from 41.22 to 65.39 .

Out of 18 clinical and three reference strains of $C$. albicans, 13 strains formed moderate to strong biofilms. Three strains produced weak biofilms and two strains could not form biofilms (Table 1 and Figure 1C). Reference strains C. albicans NRRLY12983 and C. albicans SC5314 formed strong biofilms with absorbance values of $>1.0$. Among the 6 non-albicans Candida, only C. tropicalis 01 formed weak biofilm and others were negative. Among the test strains, non-hydrophobic strains (viz. C. albicans 02, 08, 10-12, C. glabrata 02, C. glabrata MTCC3019 and C. tropicalis 02) were either non-biofilm or weak biofilm formers.

\section{GC-GC/MS analysis}

GC and GC-MS analysis of essential oils revealed the presence of various major and minor compounds. Main C. copticum oil components were $\rho$-cymene (33.67\%), thymol (22.82\%) and $\gamma$-terpinene (21.61\%). Thymol was the main constituent $(44.71 \%)$ of $T$. vulgaris followed by $\gamma$-terpinene $(26.01 \%)$ and $\alpha$-cymene $(21.22 \%)$ (Tables 2 and 3$)$.

\section{Susceptibility of fungal strains to essential oils and viability at sub-MICs}

As evident from Table 4, test oils exhibited MIC value in the range of $45-360 \mu \mathrm{g} / \mathrm{ml}$ against one or other strains. There was no significant $(P<0.05)$ decrease observed in $\log \mathrm{cfu}$ in the test strains of $C$. albicans at cell density of $1.0 \times 10^{6}$ cfu.mL ${ }^{-1}$ treated with $0.25 \times$ and $0.5 \times$ MICs of test agents compared to untreated control at equal cell density (Table 5).

Table 2 Major active compounds of $C$. copticum as identified by GC/GC-MS analysis

\begin{tabular}{llll}
\hline Peak no. & Retention indices & Compound identified & $\%$ area \\
\hline 1 & 939 & a-pinene & 4.5 \\
4 & 980 & $\beta$-pinene & 12.3 \\
7 & 992 & $\beta$-myrcene & 2.6 \\
10 & 1033 & a-limonine & 0.6 \\
12 & 1061 & p-terpinene & 21.6 \\
13 & 1017 & p-cimene & 33.8 \\
15 & 1096 & a-dimethyl styrene & 0.8 \\
17 & 1109 & limonene o $\times$ ide & 0.5 \\
22 & 1288 & thymol & 22.8 \\
\hline
\end{tabular}

Table 3 Major active compounds of $T$. vulgaris as identified by GC/GC-MS analysis

\begin{tabular}{llll}
\hline Peak no. & $\begin{array}{l}\text { Retention } \\
\text { indices }\end{array}$ & Compound identified & \% area \\
\hline 1 & 936 & a-pinene & 1.1 \\
3 & 977 & $\beta$-pinene & 0.5 \\
5 & 1033 & a-limonine & 0.5 \\
7 & 1061 & Y-terpinene & 26.0 \\
8 & 1023 & a-cimene & 21.2 \\
11 & 1078 & Z,6-dimethyl-3,5,7-octriene-olstyrene & 0.5 \\
17 & 1288 & thymol & 44.7 \\
19 & 1318 & carvacrol & 0.9 \\
22 & 1514 & 1,4-inden-1-one & 0.6 \\
24 & 1564 & 3-pentene-2-one & 1.1 \\
\hline
\end{tabular}

Table 4 Sensitivity of strains of Candida spp to oils of C. copticum, T. vulgaris and thymol

\begin{tabular}{|c|c|c|c|}
\hline \multirow[t]{2}{*}{ Test strains } & \multicolumn{3}{|c|}{ MIC $\left(\mu \mathrm{g} \cdot \mathrm{mL}^{-1}\right)$} \\
\hline & C. copticum & T. vulgaris & Thymol \\
\hline \multicolumn{4}{|l|}{ C. albicans } \\
\hline C. albicans 01 & 360 & 180 & 90 \\
\hline C. albicans 02 & 180 & 180 & 90 \\
\hline C. albicans 03 & 180 & 360 & 90 \\
\hline C. albicans 04 & 180 & 360 & 180 \\
\hline C. albicans 05 & 180 & 360 & 90 \\
\hline C. albicans 06 & 360 & 360 & 180 \\
\hline C. albicans 07 & 360 & 90 & 45 \\
\hline C. albicans 08 & 180 & 90 & 45 \\
\hline C. albicans 09 & 360 & 180 & 90 \\
\hline C. albicans 10 & 360 & 90 & 90 \\
\hline C. albicans 11 & 360 & 360 & 90 \\
\hline C. albicans 12 & 90 & 180 & 90 \\
\hline C. albicans 13 & 360 & 360 & 180 \\
\hline C. albicans 14 & 360 & 360 & 180 \\
\hline C. albicans 15 & 360 & 180 & 90 \\
\hline C. albicans 16 & 360 & 360 & 90 \\
\hline C. albicans 17 & 360 & 90 & 45 \\
\hline C. albicans 18 & 180 & 180 & 45 \\
\hline C. albicans NRRLY12983 & 180 & 180 & 90 \\
\hline C. albicans MTCC183 & 180 & 90 & 90 \\
\hline C. albicans SC5314 & 45 & 90 & 90 \\
\hline C. glabrata 01 & 180 & 360 & 180 \\
\hline C. glabrata 02 & 180 & 360 & 90 \\
\hline C. glabrata MTCC3019 & 180 & 360 & 90 \\
\hline C. krusei 01 & 360 & 360 & 180 \\
\hline C. tropicalis01 & 90 & 360 & 90 \\
\hline C. tropicalis02 & 90 & 360 & 90 \\
\hline
\end{tabular}


Table 5 Viability assays of strains of Candida spp. $\mathrm{e} \times$ posed to sub-inhibitory concentrations of oils of C. copticum, T. vulgaris and thymol

\begin{tabular}{|c|c|c|c|c|c|c|c|c|}
\hline \multirow{2}{*}{$\begin{array}{l}\text { Test agents } \\
\text { (sub-MICs) }\end{array}$} & \multicolumn{8}{|c|}{ Cell viability assay (log cfu. $\mathrm{mL}^{-1}$ at $10^{5}$ dilution) } \\
\hline & C. albicans 04 & C. albicans 05 & C. albicans 07 & C. albicans 09 & C. albicans 16 & $\begin{array}{l}\text { C. albicans } \\
\text { MTCC183 }\end{array}$ & $\begin{array}{l}\text { C. albicans } \\
\text { SC5314 }\end{array}$ & C. tropicalis 01 \\
\hline Untreated & $8.14 \pm 0.02$ & $8.04 \pm 0.01$ & $8.12 \pm 0.03$ & $8.25 \pm 0.01$ & $8.02 \pm 0.04$ & $8.19 \pm 0.01$ & $8.45 \pm 0.03$ & $8.07 \pm 0.04$ \\
\hline \multicolumn{9}{|l|}{ Essential oils } \\
\hline \multicolumn{9}{|l|}{ C. copticum } \\
\hline $0.25 \times \mathrm{MIC}$ & $7.16 \pm 0.04$ & $7.29 \pm 0.07$ & $7.34 \pm 0.03$ & $7.26 \pm 0.04$ & $7.40 \pm 0.06$ & $7.38 \pm 0.05$ & $7.60 \pm 0.02$ & $7.41 \pm 0.04$ \\
\hline $0.5 \times \mathrm{MIC}$ & $6.10 \pm 0.03$ & $6.39 \pm 0.05$ & $6.46 \pm 0.04$ & $6.24 \pm 0.02$ & $6.35 \pm 0.03$ & $6.44 \pm 0.04$ & $7.17 \pm 0.01$ & $6.98 \pm 0.05$ \\
\hline \multicolumn{9}{|l|}{ T. vulgaris } \\
\hline $0.25 \times \mathrm{MIC}$ & $7.09 \pm 0.03$ & $7.24 \pm 0.06$ & $7.14 \pm 0.05$ & $7.19 \pm 0.05$ & $7.37 \pm 0.04$ & $7.32 \pm 0.05$ & $7.71 \pm 0.04$ & $7.52 \pm 0.02$ \\
\hline $0.5 \times \mathrm{MIC}$ & $6.43 \pm 0.06$ & $6.41 \pm 0.05$ & $6.39 \pm 0.07$ & $6.19 \pm 0.04$ & $6.27 \pm 0.06$ & $6.44 \pm 0.07$ & $7.02 \pm 0.04$ & $6.71 \pm 0.06$ \\
\hline \multicolumn{9}{|l|}{ Thymol } \\
\hline $0.25 \times \mathrm{MIC}$ & $7.11 \pm 0.02$ & $7.16 \pm 0.04$ & $7.23 \pm 0.06$ & $7.22 \pm 0.03$ & $7.24 \pm 0.06$ & $7.26 \pm 0.05$ & $7.44 \pm 0.07$ & $7.29 \pm 0.03$ \\
\hline $0.5 \times \mathrm{MIC}$ & $6.23 \pm 0.04$ & $6.54 \pm 0.03$ & $6.44 \pm 0.03$ & $6.33 \pm 0.06$ & $6.23 \pm 0.05$ & $6.33 \pm 0.05$ & $7.08 \pm 0.07$ & $6.45 \pm 0.05$ \\
\hline \multicolumn{9}{|c|}{ Antifungal drug } \\
\hline \multicolumn{9}{|l|}{ Fluconazole } \\
\hline $0.25 \times \mathrm{MIC}$ & $7.08 \pm 0.03$ & $7.11 \pm 0.06$ & $7.23 \pm 0.05$ & $7.16 \pm 0.05$ & $7.22 \pm 0.04$ & $7.31 \pm 0.04$ & $7.14 \pm 0.06$ & $7.31 \pm 0.05$ \\
\hline $0.5 \times \mathrm{MIC}$ & $6.18 \pm 0.04$ & $6.45 \pm 0.06$ & $6.44 \pm 0.05$ & $6.27 \pm 0.04$ & $6.15 \pm 0.06$ & $6.04 \pm 0.05$ & $7.23 \pm 0.04$ & $6.88 \pm 0.06$ \\
\hline
\end{tabular}

Within the columns, untreated means followed by treated means are non-significantly different according to Duncan's multiple range tests $(P<0.05)$.

Anti-virulence activity of essential oils against test fungi Oils of $C$. copticum, $T$. vulgaris and thymol were further assessed for their anti-virulence activity at sub-MICs against the strains C. albicans 04, 05, 07, 16, MTCC183, SC5314 and C. tropicalis 01 . These strains were selected on the basis of being producers of significant amount of proteinase or haemolysin.

\section{Effect on cell surface hydrophobicity}

As evident from Table 6, CSH in test strains was affected in varying capacity when treated with sub-MICs of oils. Test oils at both the $0.5 \times$ and $0.25 \times$ MICs were significantly $(P<0.05)$ effective in reducing the $\mathrm{CSH}$ in one or other strains. Control drug fluconazole at tested concentrations could not induce significant reduction in $\mathrm{CSH}$.

Table 6 CSH in the strains of Candida spp. exposed to sub-inhibitory concentrations of oils of C. copticum, T. vulgaris and thymol

\begin{tabular}{|c|c|c|c|c|c|}
\hline \multirow{2}{*}{$\begin{array}{l}\text { Test agents } \\
\text { (Sub-MICs) }\end{array}$} & \multicolumn{5}{|c|}{ Percent cell surface hydrophobicity } \\
\hline & C. albicans 04 & C. albicans 07 & C. albicans MTCC183 & C. albicans SC5314 & C. tropicalis 01 \\
\hline Untreated control & $61.75 \pm 3.45^{\mathrm{a}}$ & $62.74 \pm 4.35^{\mathrm{a}}$ & $33.80 \pm 3.45^{\mathrm{a}}$ & $53.28 \pm 3.45^{a}$ & $60.97 \pm 5.34^{a}$ \\
\hline \multicolumn{6}{|l|}{ Essential oils } \\
\hline \multicolumn{6}{|l|}{ C. copticum } \\
\hline $0.25 \times \mathrm{MIC}$ & $22.55 \pm 2.24^{b}$ & $21.16 \pm 2.24^{\mathrm{b}}$ & $22.69 \pm 1.91^{\mathrm{b}}$ & $25.34 \pm 2.43^{b}$ & $17.31 \pm 0.82^{b}$ \\
\hline $0.5 \times \mathrm{MIC}$ & $15.00 \pm 1.67^{b, c}$ & $17.87 \pm 1.24^{\mathrm{b}, \mathrm{c}}$ & $12.98 \pm 1.47^{c}$ & $16.72 \pm 1.81^{c}$ & $6.69 \pm 0.45^{c}$ \\
\hline \multicolumn{6}{|l|}{ T. vulgaris } \\
\hline $0.25 \times \mathrm{MIC}$ & $51.37 \pm 4.45^{b}$ & $33.70 \pm 2.34^{b}$ & $30.37 \pm 2.34^{a}$ & $40.27 \pm 3.81^{b}$ & $43.25 \pm 4.16^{b}$ \\
\hline $0.5 \times \mathrm{MIC}$ & $43.56 \pm 3.31^{b, c}$ & $24.91 \pm 1.81^{\mathrm{b}, \mathrm{c}}$ & $17.05 \pm 1.23^{b}$ & $20.18 \pm 1.67^{c}$ & $36.39 \pm 2.43^{b}$ \\
\hline \multicolumn{6}{|l|}{ Thymol } \\
\hline $0.25 \times \mathrm{MIC}$ & $33.17 \pm 2.56^{\mathrm{a}}$ & $28.00 \pm 2.67^{\mathrm{a}}$ & $29.92 \pm 2.89^{a}$ & $35.81 \pm 2.78^{\mathrm{a}}$ & $34.45 \pm 2.67^{a}$ \\
\hline $0.5 \times \mathrm{MIC}$ & $21.23 \pm 1.78^{\mathrm{a}}$ & $25.11 \pm 1.67^{b}$ & $16.64 \pm 1.78^{b}$ & $15.89 \pm 1.89^{b}$ & $17.89 \pm 1.89^{b}$ \\
\hline \multicolumn{6}{|l|}{ Antifungal drug } \\
\hline \multicolumn{6}{|l|}{ Fluconazole } \\
\hline $0.25 \times$ MIC & $61.68 \pm 4.67^{\mathrm{a}}$ & $43.07 \pm 3.89^{b}$ & $31.74 \pm 3.78^{a}$ & $46.89 \pm 3.89^{a}$ & $51.23 \pm 4.78^{\mathrm{a}}$ \\
\hline $0.5 \times \mathrm{MIC}$ & $55.93 \pm 3.56^{a}$ & $32.35 \pm 3.56^{b, c}$ & $30.89 \pm 3.78^{a}$ & $40.10 \pm 3.89^{b}$ & $43.92 \pm 3.89^{b}$ \\
\hline
\end{tabular}

Within the columns, means values followed by different letters $\left({ }^{a}, b, c\right)$ are significantly different according to Duncan's multiple range tests $(P<0.05)$. 
Table 7 Effects of sub-inhibitory concentrations of oils of C. copticum, T. vulgaris and thymol on proteinase and haemolysin productions in the strains of Candida spp

\begin{tabular}{|c|c|c|c|c|c|c|c|c|c|c|}
\hline \multirow{2}{*}{$\begin{array}{l}\text { Test agents } \\
\text { (Sub-MICs) }\end{array}$} & \multicolumn{5}{|c|}{ *Percent reduction in proteinase production over untreated control } & \multicolumn{5}{|c|}{ **Percent reduction in haemolysin production over untreated control } \\
\hline & C. albicans 04 & C. albicans 09 & $\begin{array}{l}\text { C. albicans } \\
\text { MTCC183 }\end{array}$ & C. albicans SC5314 & C. tropicalis 01 & C. albicans 05 & C. albicans 16 & C. albicans MTCC183 & C. albicans SC5314 & C. tropicalis 01 \\
\hline \multicolumn{11}{|l|}{ Essential oils } \\
\hline \multicolumn{11}{|l|}{ C. copticum } \\
\hline $0.25 \times \mathrm{MIC}$ & $89.23 \pm 4.56$ & $80.74 \pm 3.45$ & $88.50 \pm 2.34$ & $70.48 \pm 4.56$ & $63.67 \pm 2.34$ & $53.90 \pm 3.45$ & $74.70 \pm 4.56$ & $56.89 \pm 2.34$ & $56.89 \pm 3.45$ & $58.90 \pm 3.67$ \\
\hline $0.5 \times \mathrm{MIC}$ & $94.80 \pm 3.56$ & $84.59 \pm 5.67$ & $90.91 \pm 5.78$ & $82.45 \pm 4.56$ & $82.50 \pm 3.45$ & $64.13 \pm 4.56$ & $87.83 \pm 5.67$ & $77.56 \pm 3.33$ & $65.78 \pm 3.45$ & $70.89 \pm 4.56$ \\
\hline \multicolumn{11}{|l|}{ T. vulgaris } \\
\hline $0.25 \times \mathrm{MIC}$ & $92.54 \pm 5.67$ & $86.31 \pm 5.67$ & $71.99 \pm 3.67$ & $65.78 \pm 5.67$ & $75.05 \pm 4.56$ & $55.41 \pm 3.45$ & $79.47 \pm 3.45$ & $48.11 \pm 3.45$ & $50.89 \pm 4.56$ & $50.46 \pm 4.56$ \\
\hline $0.5 \times \mathrm{MIC}$ & $96.00 \pm 2.34$ & $91.45 \pm 5.67$ & $80.55 \pm 5.67$ & $74.83 \pm 4.56$ & $87.34 \pm 2.34$ & $71.05 \pm 4.56$ & $79.47 \pm 4.56$ & $63.16 \pm 3.45$ & $59.80 \pm 3.45$ & $67.10 \pm 3.45$ \\
\hline \multicolumn{11}{|l|}{ Thymol } \\
\hline $0.25 \times \mathrm{MIC}$ & $95.98 \pm 5.78$ & $89.31 \pm 4.56$ & $91.99 \pm 5.67$ & $90.78 \pm 5.67$ & $88.99 \pm 4.45$ & $65.41 \pm 2.34$ & $85.00 \pm 3.45$ & $71.11 \pm 4.57$ & $68.89 \pm 3.56$ & $66.46 \pm 4.56$ \\
\hline $0.5 \times \mathrm{MIC}$ & $97.00 \pm 5.56$ & $93.67 \pm 5.67$ & $92.65 \pm 4.67$ & $87.97 \pm 4.56$ & $90.67 \pm 3.34$ & $78.05 \pm 4.56$ & $89.47 \pm 4.56$ & $83.16 \pm 4.34$ & $69.80 \pm 3.63$ & $77.10 \pm 5.61$ \\
\hline \multicolumn{11}{|c|}{ Antifungal drug } \\
\hline \multicolumn{11}{|l|}{ Fluconazole } \\
\hline $0.25 \times \mathrm{MIC}$ & $50.32 \pm 4.47$ & $50.33 \pm 4.47$ & $44.13 \pm 3.34$ & $43.39 \pm 4.56$ & $41.57 \pm 4.56$ & $45.32 \pm 3.47$ & $49.33 \pm 3.47$ & $38.13 \pm 4.34$ & $40.39 \pm 4.56$ & $40.57 \pm 4.56$ \\
\hline $0.5 \times \mathrm{MIC}$ & $54.23 \pm 5.56$ & $57.47 \pm 4.57$ & $56.16 \pm 4.47$ & $54.80 \pm 4.45$ & $54.10 \pm 5.33$ & $51.23 \pm 4.56$ & $55.47 \pm 3.57$ & $46.16 \pm 3.47$ & $49.80 \pm 3.45$ & $51.10 \pm 3.33$ \\
\hline
\end{tabular}

${ }^{*}$ Absorbance at $280 \mathrm{~nm}$ for untreated controls were $0.442 \pm 0.009$ (C. albicans 04), $0.865 \pm 0.003$ (C. albicans 09), $1.267 \pm 0.006$ (C. albicans MTCC183), $1.032 \pm 0.043$ (C. albicans SC5314), 1.010 \pm 0.007 (C. tropicalis 01 ).
$* \%$ haemolysin production in untreated controls were $74.68 \pm 3.45$ (C. albicans 05), $83.18 \pm 5.67$ (C. albicans 16), $24.93 \pm 2.67$ (C. albicans MTCC183), $74.45 \pm 4.56$ (C. albicans SC5314), $60.42 \pm 3.45$ (C. tropicalis 01 ). 


\section{Effect on production of proteinase and haemolysin}

At both of the tested concentrations, test oils were able to reduce the production of proteinase by $>70 \%$ in test strains (Table 7). Maximum reduction of $96.0 \%$ was observed for T. vulgaris at $0.5 \times \mathrm{MIC}$ against $C$. albicans 04 . The test oils at $0.5 \times$ MIC induced $>70 \%$ reduction in the haemolytic activity of test strains. A maximum reduction of $87.83 \%$ was recorded for $C$. copticum at $0.5 \times \mathrm{MIC}$ against $C$. albicans 16. $T$. vulgaris at both the tested concentrations induced a reduction of $79.47 \%$ against this strain (Table 7).

\section{Inhibition of biofilms}

As presented in Table 8, varying level of attenuation in the biofilm formation by $C$. albicans cells was observed in the presence of essential oils. Biofilm formation in both the test strains was reduced maximally by thymol. At the treatment of $0.5 \times \mathrm{MIC}$ and $0.25 \times \mathrm{MIC}$ of this oil, 6.90 to $8.34 \%$ formation of biofilm was recorded in test strains. Whereas fluconazole at $0.5 \times \mathrm{MIC}$ led to $48.16 \%$ formation of biofilm in C. albicans 04 . Similar pattern of biofilm formation was also recorded for test oils and drugs against C. albicans SC5314.

\section{Scanning electron microscopy of sessile cells}

Untreated cells resulted in intact biofilm formation with dense matrix and multilayered network of yeast cells and hyphae leading to a compact three dimensional structure (Figure 2A). The treated cells $\left(90 \mu \mathrm{g} \mathrm{ml}^{-1}\right.$ of $C$. copticum) exhibited loosening of cells and disappearance of matrix. Filamentation is inhibited and destruction of cell membrane in biofilm was observed (Figure 2B,C). Untreated sessile cells showed smooth cell membrane (Figure 2a. inset) whereas treatment with oils exhibited shrinkage and lysis in cell membranes of sessile cells (Figure 2b. inset and c. inset). Similar effects were also observed for thymol (Figure 2D, and d. inset).

\section{Transmission electron microscopy of planktonic cells} In untreated sample of Candida cells, organelles such as nuclei, mitochondria and nucleus are appeared to

\section{Table 8 Effects of oils of C. copticum, T. vulgaris and thymol on biofilm formation in drug-resistant and -sensitive strains of C. albicans}

\begin{tabular}{|c|c|c|c|c|}
\hline \multirow[t]{3}{*}{ Test agents } & \multicolumn{4}{|c|}{ Biofilm formation } \\
\hline & \multicolumn{2}{|c|}{ C. albicans 04} & \multicolumn{2}{|c|}{ C. albicans SC5314 } \\
\hline & $0.5 \times \mathrm{MIC}$ & $0.25 \times \mathrm{MIC}$ & $0.5 \times \mathrm{MIC}$ & $0.25 \times \mathrm{MIC}$ \\
\hline \multicolumn{5}{|l|}{ Essential oils } \\
\hline C. copticum & $25.32 \pm 2.68$ & $40.08 \pm 3.69$ & $28.50 \pm 2.41$ & $42.92 \pm 2.48$ \\
\hline T. vulgaris & $07.49 \pm 0.98$ & $11.70 \pm 1.91$ & $14.72 \pm 1.05$ & $25.04 \pm 2.54$ \\
\hline Thymol & $07.59 \pm 1.69$ & $08.34 \pm 1.93$ & $06.90 \pm 1.34$ & $07.85 \pm 1.18$ \\
\hline \multicolumn{5}{|c|}{ Antifungal drug } \\
\hline Fluconazole & $48.16 \pm 0.97$ & $67.61 \pm 1.39$ & $48.63 \pm 2.24$ & $65.34 \pm 3.32$ \\
\hline
\end{tabular}

be normal (Figure 3A). Treated sample exhibited several changes including thickening of cell wall, stretching of cell membrane, leakage of cell wall and cell membrane, deposition of lipid globules, excessive vacuolization and abnormal distribution of polysaccharides leading to deterioration of cytoplasmic contents (Figure 3B-F).

\section{Discussion}

Efficient treatment for fungal infections has become very important as the frequency of life-threatening fungal diseases is increasing due to the progress in the treatment of critically ill patients whose immune status has been deteriorated. Furthermore, high doses drug toxicity and emergence of drug-resistant strains have added extra burden for currently available antifungal therapy. Therefore, development of novel antifungal agents or strategies that are effective against pathogens that are resistant to currently available antifungal drugs is of paramount importance. Considering this, we attempted to investigate concentration dependent effect of two essential oils namely C. copticum and T. vulgaris and their major active compound thymol against growth and virulence factors production viz. proteinase and haemolysin and biofilm formation in the drug-resistant strains of Candida spp.

Our data has highlighted the production of proteinase and haemolysin in the test strains of Candida spp irrespective of their source of clinical conditions. Productions of these virulence factors are in agreement of reports of other workers [39-41]. Furthermore, hydrophobicity seems to be associated with biofilms forming ability of the strains. This could be a very serious threat for removal of infections caused by drug-resistant strains especially by conventional antifungal drugs such as amphotericin B and azoles because of their limitations due to host toxicity and drugresistance [9]. These test oils were found to be non-toxic at sub-MICs. Thymol was the major active ingredient of both the test oils as revealed by GC/GC-MS analysis and found to be in agreement with the literature $[16,19,20]$. Moreover, thymol was found to be more effective in all the inhibitory assays. This indicates that inhibitory activity of the oils of C. copticum and T. vulgaris is largely due to the thymol. However, minor constituents may also play a key role in the biological activities of these oils.

In this study, all the oils at tested sub-MICs significantly reduced the $\mathrm{CSH}$ in test strains. Hydrophobic cells are more adherent and resistant to phagocytosis and, therefore more virulent than hydrophilic cells. In this regard, lowering of $\mathrm{CSH}$ by test oils suggests their importance in arresting the candidal colonization in pathogenesis. Furthermore, our findings have revealed strong inhibition of proteolytic activity by test oils at $0.25 \times$ and $0.5 \times$ MICs. Secreted aspartyl proteinases (SAPs) degrade many lesion proteins at lesion sites, such as albumin, hemoglobin, keratin, and secretory immunoglobulins A [42]. These 


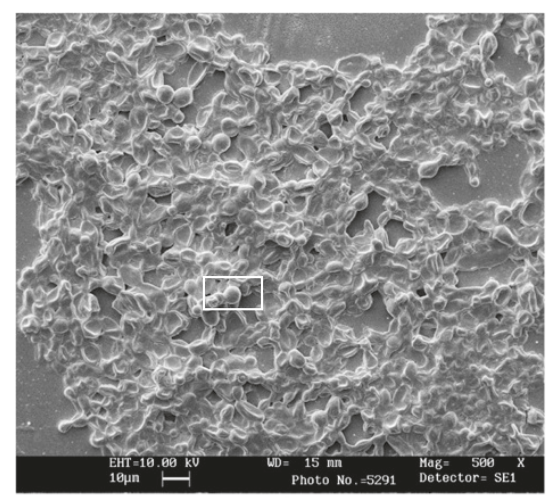

A

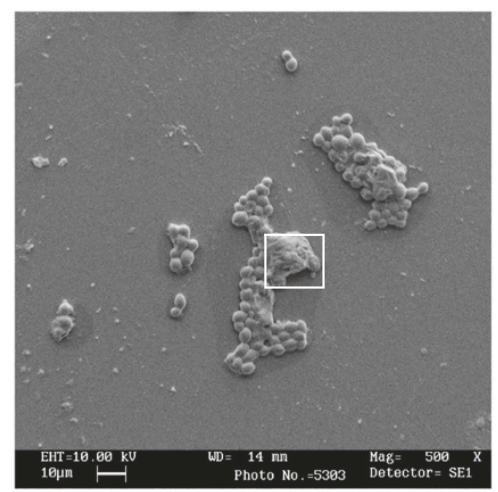

C

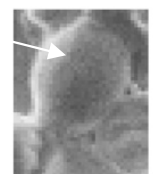

(a. inset)

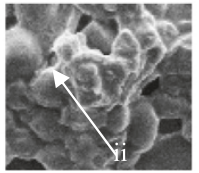

(b. inset)

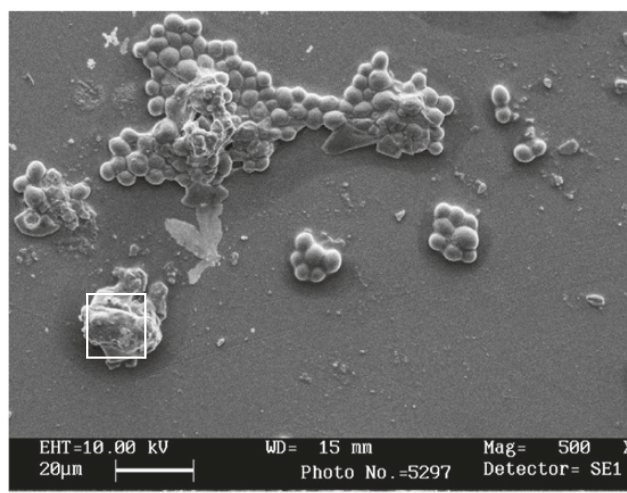

B

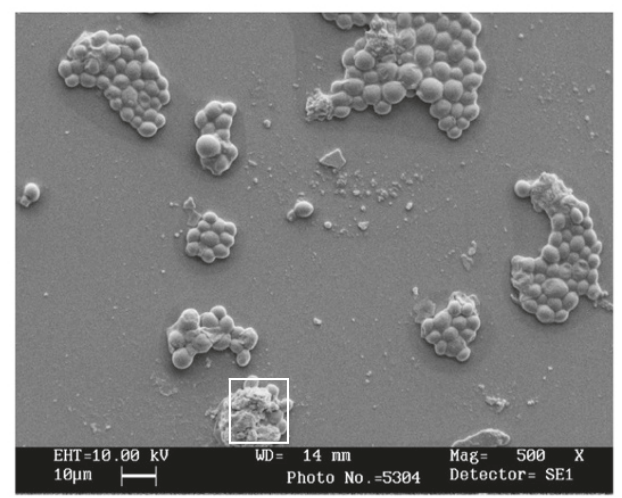

D

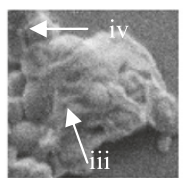

(c. inset)

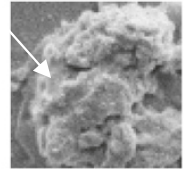

(d. inset)

Figure 2 Scanning electron micrograph of the $48 \mathrm{~h}$ biofilm formed in C. albicans 04 on catheter discs in the absence and presence of sub-MICs of oils. (A) Biofilm formed without oils (a. inset) arrow indicates smooth cell membrane of normal cell. (B) Biofilm formed in the presence of C. copticum at $90 \mu \mathrm{g} \cdot \mathrm{mL}^{-1}$ (b. inset) bursting of cells leading to vesicle formation due to lytic material (ii). (C) Biofilm formed in the presence of T. vulgaris at $90 \mu \mathrm{g} \cdot \mathrm{mL}^{-1}$ (c. inset) cell membrane shrinkage in sessile cells (iii), empty cells (iv). (D) Biofilm formed in the presence of thymol at $90 \mu \mathrm{g} \cdot \mathrm{mL}^{-1}$ (d. inset) lysis of membrane and release of cellular material (v).

proteolytic activities of SAPs are important for the virulence of Candida spp. Therefore, inhibition of extracellular production of proteinase will weaken the colonization of Candida cells and will be easily evaded by immune cells. Also, test oils effectively inhibited the haemolysin production at $0.25 \times$ MIC. In our knowledge, there is no report on inhibition of haemolysin production in C. albicans by essential oils. There are reports that high concentrations of azole drugs cause an increased Sap activity in resistant isolates [43]. AMB-resistant strain developed from C. albicans ATCC10231 exhibited enhanced activity of virulence factors like extracellular secreted aspartyl proteinase [44]. In this perspective, oils of C. copticum, T. vulgaris and thymol exhibiting anti-virulence activity along with conventional antifungal drugs will be of great advantage in controlling the increase in virulence of drug-resistant strains. Drug-resistant strains exhibiting production of virulence factors will be more serious in case of immunocompromised patients where relapses of infection occurs because high doses can not be given and weakened immune system could not clear the infection. The use of anti-virulence agent at lower doses of sub-inhibitory concentration will assist in combating such problems.

Furthermore, our data showed that $77 \%$ of C. albicans strains were strong biofilm formers. This may reflect similarities in the ability of strains of C. albicans from different sites of infection to form biofilms and strengthen the reports from other workers that most of the Candida infections are associated with biofilm forming ability of Candida spp. We evaluated oils of C. copticum, T. vulgaris 


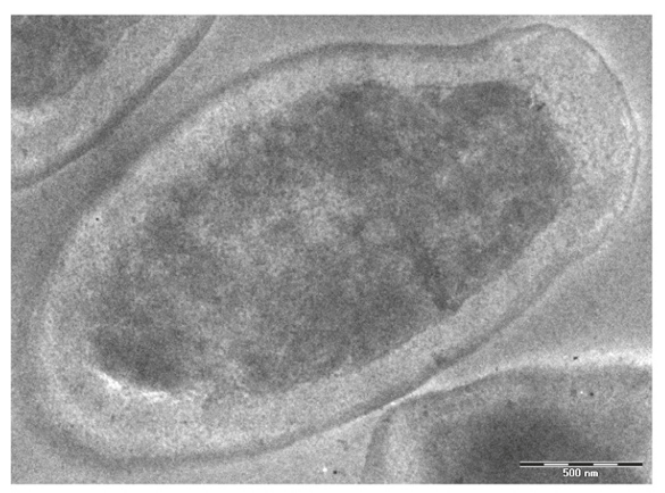

A

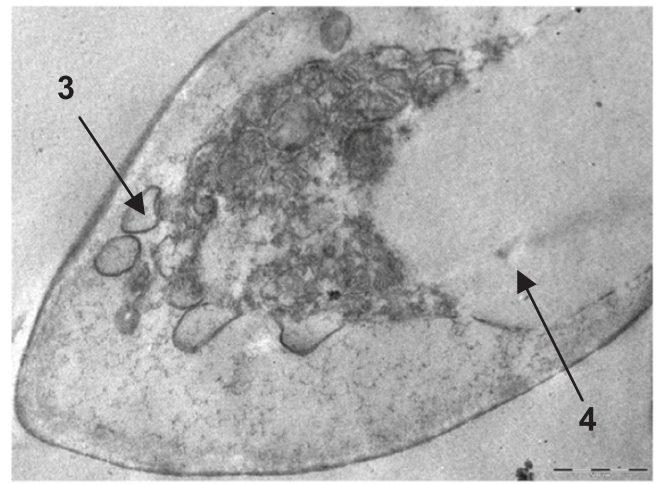

C

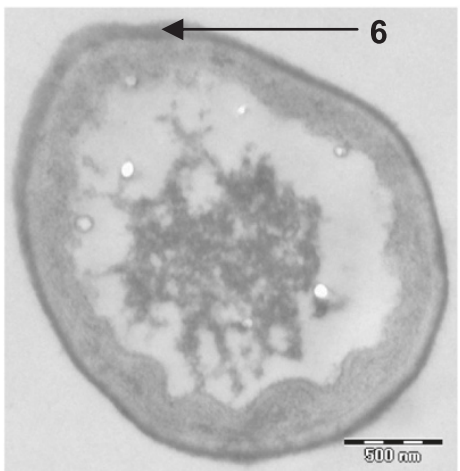

E

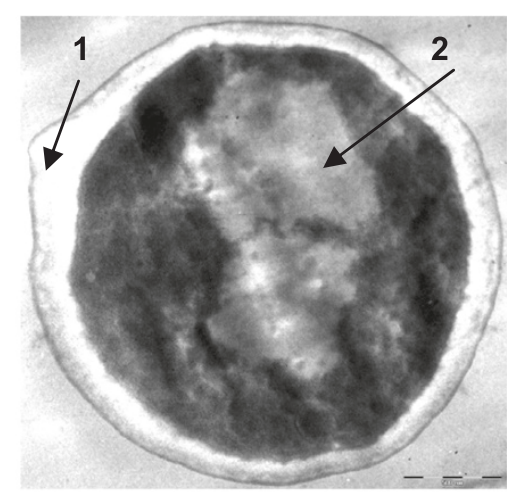

B

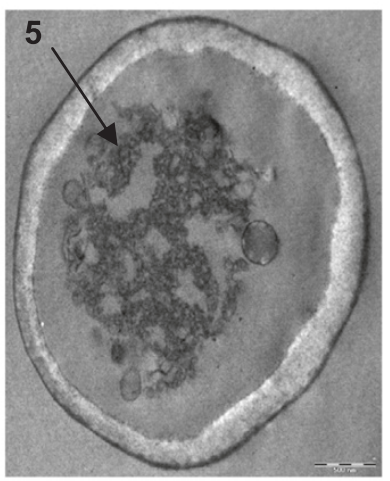

D

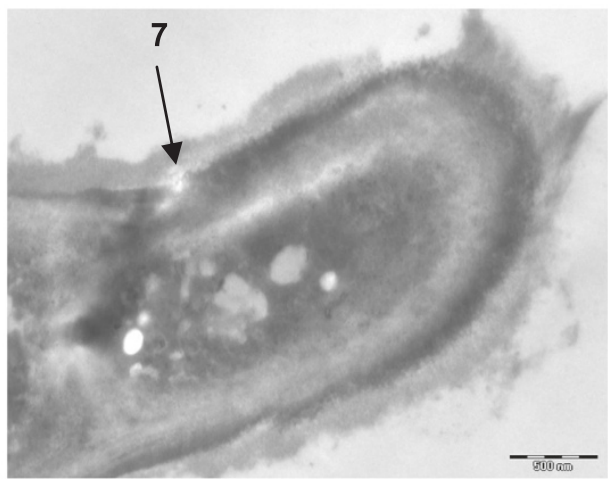

$\mathbf{F}$

Figure 3 Transmission electron micrograph of the $48 \mathrm{~h}$ grown C. albicans 04 cells in the absence and presence of sub-MICs of oils. (A) Untreated; intact cell wall, cell membranes and other organelles. (B, C) Cells grown in the presence of C. copticum at 90 Mg.mL ${ }^{-1}$; loosening of cell membrane (1), disorganized cytoplasm (2), deposition of lipid globules (3), excessive vacuolization (4). (D,E) Cells grown in the presence of T. vulgaris at $90 \mu \mathrm{g} \cdot \mathrm{mL}^{-1}$; disorganized protoplasm with receding of cell membrane (5), thickening of cell wall (6). (F) Cells grown in the presence of thymol at $90 \mu \mathrm{g} \cdot \mathrm{mL}^{-1}$; lysis of cell wall and shrinkage of cell (7).

and thymol at sub-MICs for their ability to inhibit the formation of biofilms. If an agent is added at the beginning of the experiment, the agent might act before the biofilm formed and inhibit development of biofilm; it could be of greater interest in combating recalcitrant infections of Candida biofilms. Our data revealed varying level of attenuation of biofilm formation by planktonic Candida cells in the presence of test oils and drugs in a dose dependent manner. Among the tested agents, thymol showed most inhibitory effect on biofilm formation at $0.5 \times$ and $0.25 \times$ MIC followed by $T$. vulgaris and $C$. copticum. Control drug fluconazole was less effective in preventing the formation of biofilms. The concentration dependent inhibition of biofilm formation was 
visually confirmed by scanning electron microscopy of $C$. albicans 04. In our study, SEM observations have revealed intact biofilm formation by untreated cells in $48 \mathrm{~h}$ whereas treated cells exhibited disorganization of biofilm stages. This is appeared to be because of interference of oils with cell membrane integrity as evidenced by shrinkage of cell surface and lysis of sessile cells. Similar observations were reported by Braga et al. [45] for thymol and eugenol against planktonic cells of $C$. albicans. This indicates that Candida cells in both the planktonic and biofilm stages are affected in a similar fashion and cells in biofilm stage can not gain increased tolerance to test oils as it attains against conventional antifuingal drugs. TEM observations of treated Candida cells indicate that mode of action of such compounds are disrupting the overall intracellular endomembranous system. Therefore, it appears that cell wall and cell membrane integrity, along with other membranous structures are the target sites of these compounds. The hydrophobic and volatile nature of oils may result in their increased uptake through charged polysaccharides of extracellular matrix of biofilms making more cells in contact to oils and exerting greater membrane permeation into Candida cells. This may result in an increased spectrum of action of these oils on sessile cells including persister cells leading to a retarded or disorganized development of biofilms.

\section{Conclusions}

In conclusion, the non-growth inhibitory concentrations i.e. sub-MICs of oils of C. copticum and T. vulgaris could influence the production of proteinase and haemolysin and biofilm formation. These activities appeared to be due to the presence of thymol in these oils. Inhibition of production of proteinase and haemolysin factors and biofilms by these oils will add to their efficacy as anti-pathogenic agents. A potential advantage of this approach is that new antimicrobials aimed at inhibiting virulence rather than growth may impose weaker selective pressure for the development of antibiotic resistance relative to current antibiotics. Novel therapeutics that target virulence rather than simply in vitro cell growth would both supplement and add diversity to our current antimicrobial armamentarium However, pharmacokinetic studies are needed to ensure the toxicity and anti-pathogenic ability of these oils under in vivo to establish their therapeutic potential.

\section{Competing interests}

The authors have declared no competing interests.

\section{Authors' contributions}

MSAK carried out the experimental work, data interpretation and manuscript writing. IA supervised the work and revised the draft. SSC and FB helped in microscopic assays and revised the draft. All authors have read and approved the final manuscript.

\section{Acknowledgments}

We are thankful to Sophisticated Analytical Instrument Facility, All India Institute of Medical Sciences, New Delhi for providing electron microscope for our work. We sincerely acknowledge the Indian Council of Medical Research, New Delhi for financial support in the form of SRF to M S A Khan.

\section{Author details}

${ }^{1}$ Phytomedicine Programme, Department of Paraclinical Sciences, University of Pretoria, Pretoria 0110, South Africa. ${ }^{2}$ Department of Agricultural Microbiology, Aligarh Muslim University, Aligarh 202002, India.

${ }^{3}$ Environmental Biotechnology and Microbial Biochemistry Laboratory,

Institute of Microbial Technology, Chandigarh 160036, India.

Received: 23 April 2014 Accepted: 20 August 2014

Published: 15 September 2014

\section{References}

1. Pfaller MA, Diekema DJ: Epidemiology of invasive candidiasis: a persistent public health problem. Clin Microbiol Rev 2007, 20:133-163.

2. Wisplinghoff $H$, Bischoff $T$, Tallent $S M$, Seifert $H$, Wenzel RP, Edmond MB: Nosocomial bloodstream infections in US hospitals: Analysis of 24,179 cases from a prospective nationwide surveillance study. Clin Infect Dis 2004, 39:309-317.

3. Fiedel PL Jr, Vazquez JA, Sobel JD: Candida glabrata: a review of epidemiology, pathogenesis, and clinical disease with comparison to $C$. albicans. Clin Microbiol Rev 1999, 12:80-96

4. Macphail GL, Taylor GD, Buchanan-Chell M, Ross C, Wilson S, Kureishi A: Epidemiology, treatment and outcome of candidemia: a five-year review at three Can hospitals. Mycoses 2002, 45:141-145.

5. Pfaller MA, Jones RN, Marshall SA, Coffman SL, Hollis RJ, Edmond MB, Wenzel RP: Inducible amp C beta-lactamase producing gram-negative bacilli from blood stream infections: frequency, antimicrobial susceptibility, and molecular epidemiology in a national surveillance program (SCOPE). Diag Microbiol Infect Dis 1997, 28:211-219.

6. Chander J, Singla N, Sidhu SK, Gombar S: Epidemiology of Candida blood stream infections: experience of a tertiary care centre in North India. J Infect Dev Ctries 2013, 7:670-675.

7. Crump JA, Collignon PJ: Intravascular catheter-associated infections. Eur J Clin Microbiol Infect Dis 2000, 19:1318-1322.

8. Douglas LJ: Candida biofilms and their role in infection. Trends Microbiol 2003, 100:30-36

9. Gupte M, Kulkarni P, Ganguli BN: Antifungal antibiotics. App/ Microbiol Biotechnol 2002, 58:46-57.

10. Ahmad I, Beg AZ: Antimicrobial and phytochemical studies on 45 Indian medicinal plants against multi-drug resistant human pathogens. J Ethnopharcol 2001, 74:113-123.

11. Cavaleiro C, Pinto E, Goncalves MJ, Salgueiro L: Antifungal activity of Juniperus essential oils against dermatophyte, Aspergillus and Candida strains. J Appl Microbiol 2006, 100:1333-1338.

12. Tavares AC, Goncalves MJ, Cavaleiro C, Cruz MT, Lopes MC, Canhoto J, Salgueiro LR: Essential oil of Daucuscarota subsp. halophilus: composition, antifungal activity and cytotoxicity. J Ethnopharmacol 2008, 119:129-134.

13. Tempone AG, Sartorelli P, Teixeira D, Prado FO, Calixto IA, Lorenzi H, Melhem MS: Brazilian flora extracts as source of novel antileishmanial and antifungal compounds. Mem Inst Osw Cruz 2008, 103:443-449.

14. Giordani R, Regli P, Kaloustian J, Mikail C, Abou L, Portugal H: Antifungal effect of various essential oils against Candidaalbicans. Potentiation of antifungal action of amphotericin B by essential oil from Thymus vulgaris. Phytother Res 2004, 18:990-995.

15. Pina-Vaz C, Rodriques AG, Pinto E, Costa-de-Oliveira S, Tavares C, Salqueiro L, Cavaleiro C, Goncalves MJ, Martinez-de-Oliveira J: Antifungal activity of Thymus oils and their major compounds. Europ Acad Dermatol Venereol 2004, 18:73-78

16. Pinto E, Pina-Vaz C, Salgueiro L, Goncalves MJ, Costa-de-Oliveira S, Cavaleiro C, Palmeira A, Rodrigues A, Martinez-de-Oliveira J: Antifungal activity of the essential oil of Thymus pulegioides on Candida, Aspergillus and dermatophyte species. J Med Microbio/ 2006, 55:1367-137.

17. Pirbalouti AG, Bahmani M, Avijgan M: Anti-Candida activity of some of the Iranian medicinal plants. Elect J Biol 2009, 5:85-88. 
18. Hussain SS, Agoumi A, Amghar S, Boukachabine K: Anticandida activity of the marketed essential oil of Thymus vulgaris $L$ and its concomitant action with amphotericin B. Therapie 2011, 66:167-169.

19. Jamali CA, Bouzidi LE, Bekkouche K, Lahcen H, Markouk M, Wohlmuth $H$, Leach D, Abbad A: Chemical composition and antioxidant and anticandidal activities of essential oils from different wild moroccan Thymus species. Chem Biodiver 2012, 9:1188-1197.

20. Tullio V, Mandras N, Allizond V, Nostro A, Roana J, Merlino C, Banche G, Scalas D, Cuffini AM: Positive interaction of thyme (red) essential oil with human polymorphonuclear granulocytes in eradicating intracellular Candida albicans. Planta Med 2012, 78:1633-1635.

21. Kavoosi G, Tafsiry A, Ebdam AA, Rowshan V: Evaluation of antioxidant and antimicrobial activities of essential oils from Carum copticum Seed and Ferula assafoetida Latex. J Food Scie 2013, 78:T356-T361.

22. Naglik JR, Challacombe SJ, Hube B: Candida albicans secreted aspartyl proteinases in virulence and pathogenesis. Microbiol Mol Biol Rev 2003, 67:400-428.

23. Odds FC: Candida and candidosis. London: Bailliere Tindall; 1988.

24. Ibrahim AS, Mirbod F, Filler SG, Banno Y, Cole GT, Kitajima Y, Edwards JE, Nozawa Y, Ghannoum MA: Evidence implicating phospholipase as a virulence factor of Candida albicans. Infect Immun 1995, 63:1993-1998.

25. Hoegl L, Ollert M, Korting HC: The role of Candida albicans secreted aspartyl proteinase in the development of candidoses. J Mol Med 1996, 74:135-142.

26. Almeida RS, Wilson D, Hube B: Candida albicans iron acquisition within the host. FEMS Yeast Res 2009, 9:1000-1012.

27. Potera C: Forging a link between biofilms and disease. Science 1999, 283:1837-1839.

28. Khan MSA, Malik A, Ahmad I: Anti-candidal activity of essential oils alone and in combination with amphotericin $B$ and fluconazole against multidrug resistant isolates of Candida albicans. Med Mycol 2012, 50:33-42.

29. Aoki S, Itokuwa S, Nakamura Y, Nasuhara T: Comparative pathogenicity of wild type strains and respiratory mutants of Candida albicans in mice. Zent Bakteriol 1990, 273:332-343.

30. Kuriyama T, Williams DW, Lewis MAO: In vitro secreted aspartyl proteinase activity of Candida albicans isolated from oral diseases and healthy oral cavities. Oral Microbiol Immunol 2003, 18:405-407.

31. MacDonald F, Odds FC: Inducible proteinase of Candida albicans in diagnostic serology and in the pathogenesis of systemic candidosis. J Med Microbiol 1980, 13:423-435.

32. Luo G, Samaranayake LP, Yau JYY: Candida species exhibit differential in vitro hemolytic activities. J Clin Microbiol 2001, 39:2971-2974.

33. Manns JM, Mosser DM, Buckley HR: Production of hemolytic factor by Candida albicans. Infect Immun 1994, 62:5154-5156.

34. Rosenberg M, Gutnick D, Rosenberg E: Adherence of bacteria to hydrocarbons: A simple method for measuring cell-surface hydrophobicity. FEMS Microbiol Lett 1980, 9:29-33.

35. Ramage G, Vande-Walle K, Wickes B, Lopez-Ribot JL: Standardized method for in vitro antifungal susceptibility testing of Candida albicans biofilms. Antimicrob Agents Chemother 2001, 45:2475-2479.

36. Shibamoto T: Retention indices in essential oil analysis. In Capillary gas Chromatography in Essential Oil Analysis. Edited by Sandra P, Bicchi C. New York: HuethigVerlag; 1987:259-274.

37. Davies NW: Gas chromatographic retention indices of monoterpenes and sesquiterpenes on methyl silicone and carbowax $20 \mathrm{M}$ phases. J Chromatogr A 1990, 503:1-24.

38. Adams RP: Identification of essential oil components by gas chromatography/ quadrupole mass spectroscopy. Carol Stream IL: Allured Publ Corp; 2001.

39. Tsang CSP, Chu FCS, Leung WK, Jin LJ, Samaranayake LP, Siu SC: Phospholipase, proteinase and haemolytic activities of Candida albicans isolated from oral cavities of patients with type 2 diabetes mellitus. J Med Microbiol 2007, 56:1393-1398.

40. Akcaglar S, Ener B, Tore O: Acid proteinase enzyme activity in Candida albicans strains: a comparison of spectrophotometry and plate methods. Turk J Biol 2011, 35:559-567.

41. Sachin CD, Ruchi K, Santosh S: In vitro evaluation of proteinase, phospholipase and haemolysin activities of Candida species isolated from clinical specimens. Int J Med Biomed Res 2012, 1:153-157.

42. Hube B, Ruchel R, Monod M, Sanglard D, Odds FC: Functional aspects of secreted Candida proteinases. Adv Exp Med Biol 1998, 436:339-344
43. Costa CR, Jesuino RSA, Lemos JA, Fernandes OFL, e Souza LKH, Passos XS, Silva MRR: Effects of antifungal agents in Sap activity of Candida albicans isolates. Mycopathologia 2010, 169:91-98.

44. Kumar R, Shukla PK: Amphotericin B resistance leads to enhanced proteinase and phospholipase activity and reduced germ tube formation in Candida albicans. Fung Biol 2010, 114:189-197.

45. Braga PC, Sasso MD, Culici M, Alfieri M: Eugenol and thymol, alone or in combination, induce morphological alterations in the envelope of Candida albicans. Fitoterapia 2007, 78:396-400.

doi:10.1186/1472-6882-14-337

Cite this article as: Khan et al:: Sub-MICs of Carum copticum and Thymus vulgaris influence virulence factors and biofilm formation in Candida spp. BMC Complementary and Alternative Medicine 2014 14:337.

\section{Submit your next manuscript to BioMed Central and take full advantage of:}

- Convenient online submission

- Thorough peer review

- No space constraints or color figure charges

- Immediate publication on acceptance

- Inclusion in PubMed, CAS, Scopus and Google Scholar

- Research which is freely available for redistribution 